\title{
Spatial Econometric Analysis of the Effect of Government Governance on Regional Emission Reduction: Evidence from China
}

\author{
Yuanhua Yang ${ }^{1 *}$, Guohua Niu' ${ }^{2}$, Dengli Tang ${ }^{3}$, Mengjue Zhu ${ }^{1}$ \\ ${ }^{1}$ School of Public Management, Guangdong University of Finance and Economics, Guangzhou, China \\ ${ }^{2}$ Personnel Education Department, Foshan Municipal Local Taxation Bureau, Foshan, China \\ ${ }^{3}$ School of Business Administration, Guangdong University of Finance and Economics, Guangzhou, China
}

Received: 29 July 2017

Accepted: 21 November 2017

\begin{abstract}
This paper analyzes the spatial distribution characteristics of carbon dioxide $\left(\mathrm{CO}_{2}\right)$ emissions in 30 Chinese provinces from 2002 to 2013, and systematically examines the relationship between government and $\mathrm{CO}_{2}$ emissions from the level of regional legal regulation, the level of public expenditure, and corruption. Research results show that the global Moran's I values of carbon emissions from 2002 to 2013 falls between 0.2 and 0.3 , and spatial lag coefficient $\rho$ stands at 0.2340 , indicating that $\mathrm{CO}_{2}$ emissions in the region increase by $0.234 \%$ for each additional $1 \%$ of $\mathrm{CO}_{2}$ emissions in the adjacent areas, which means carbon emissions exist in a remarkable spatial autocorrelation and spatial clustering phenomenon. Then the empirical results find that the level of legal regulation and the level of regional corruption are significantly negatively correlated with regional $\mathrm{CO}_{2}$ emissions, while the level of public expenditure is significantly positively correlated with regional $\mathrm{CO}_{2}$ emissions. The results also demonstrate the inverted "U"-shaped relationship between economic income and $\mathrm{CO}_{2}$ emissions. Based on empirical results, this paper provides beneficial policy recommendations for reducing carbon emissions.
\end{abstract}

Keywords: $\mathrm{CO}_{2}$, emission reduction, government governance, spatial autocorrelation

\section{Introduction}

Environmental pollution and ecological imbalance have become the two major threats facing mankind. With the development of the economy, industrialization, and urbanization, China's ecological environment has suffered serious damage [1]. As a result, the Chinese government is stepping up its governance efforts, especially on carbon dioxide emissions. On April 25,

*e-mail: 260782245@qq.com
2007, the National Development and Reform Commission formulated the first energy conservation and emission reduction regulation - namely a comprehensive energy savings and emission reduction working plan [2]. As of 2016, the Chinese government has issued 7 major emissions reduction regulations at the national level, more than 40 local institutions have published local energy conservation and emission reduction regulations, and the total regulations exceed 1,200 [3]. Apart from the development of sound laws and regulations, the local government has also strengthened the collection of sewage charges and stepped up the investment in 
the control of environmental pollution, and more than 30 regional governments established special funds to support emission reduction projects all over the country in 2016 [3-4].

Energy conservation and emission reduction have become a basic state policy. On 30 December 2015 Chinese President Xi attended the conference of Parties and delivered an important speech titled "Work Together to Build a Win-Win, Equitable and Balanced Governance Mechanism on Climate Change." "In its intended nationally determined contributions," he said, "China pledges to peak carbon dioxide emissions by around 2030 and strives to achieve this as soon as possible, and by 2030 reduce carbon dioxide per unit of GDP by $60-65 \%$ over the 2005 level, raise the share of non-fossil fuels in primary energy consumption to about $20 \%$, and increase forest stock by around 4.5 billion cubic meters over 2005 " [3].

The realization of these urgent goals of emissions reductions hinges on better governance. So, what is governance and how does it affect emissions reductions? The most widely accepted definition of governance was proposed by Kaufmann (1999). He held that governance covered the following aspects: the right to speak, accountability system, political stability, the rule of law, regulatory quality, and corruption control [5]. Acemoglu et al. (2005) argued that a sound system was conducive to safeguarding the legitimate rights and interests of market participants [6]. It can be seen that governance is a rich concept, and it is difficult to give it an accurate definition.

However, many scholars have studied the impact of governance on regional emissions reductions from different perspectives. Some scholars believed that environmental regulation is the most effective way for protecting resources and controlling pollution, and it is also very important for China realizing energy-saving and emission-reduction targets that construct a rational environmental regulation policy system [7-9]. Gani (2012) pointed out the significant negative correlation between the level of legal regulation and $\mathrm{CO}_{2}$ emissions [10]. Zhang et al. (2014) believed that environmental regulation would not only have a direct impact on carbon emissions, but also exert an indirect impact on energy consumption structure [11]. Huang et al. (2014) and Xiu and Liu (2014) also found that environmental regulation has an important impact on regional emissions reductions[12-13]. Hampf and Rødseth (2014) analyzed the economic effects of implementing the U.S. EPA's newly proposed regulations for $\mathrm{CO}_{2}$ on existing U.S. coal-fired power plants, and found that by adopting best practices current profits can be maintained even if an intensity standard of 0.88 tons of $\mathrm{CO}_{2}$ per $\mathrm{MWh}$ is implemented [14]. Huang and Gao (2016) showed that environmental regulations have an inverted "U"-shaped impact on the efficiency of energy conservation and emission reduction [15]. Cheng et al. (2017) found that there are both significant positive global autocorrelation and local spatial cluster effects relating to pollutant emissions and technical progress [16].
More scholars have studied the relationship between corruption and the environmental Kuznets curve and found that corruption has an important impact on environmental quality [17-22]. Based on the EKC hypothesis, Cole (2007) discovered the positive impact of corruption on per capita $\mathrm{CO}_{2}$ and $\mathrm{SO}_{2}$ emissions [18]. Leitão (2011), Shackleton et al. (2012) and Khan et al. (2014) showed that the control of corruption was a significant governance factor reducing $\mathrm{CO}_{2}$ emissions [23-25]. Sundström (2013) argued that a country might not be able to enforce strict environmental regulations amidst the prevalence of corruption [26]. Zhang et al. (2016) found that the effect was negative in lower emissions countries but weak in higher emitters in APEC [27]. Sekrafi and Sghaier (2016) believed that corruption has an indirect effect on economic growth through energy consumption and environmental quality, an indirect effect on environmental quality through economic growth, and an indirect effect on energy consumption through $\mathrm{CO}_{2}$ emissions and GDP [28].

In addition, government expenditure also has an important effect on environmental output [29]. Galinato (2013) found that an increase in total government spending significantly increased forest land clearing for agricultural production in the short run, and then more carbon dioxide emissions will be produced [30]. Xiao et al. (2013) showed that the direct impact of local government spending on $\mathrm{CO}_{2}$ emissions was significantly negative in China [31]. Fritzsche and Jeff (2013) described a revision of the 2002 greenhouse gas emission reduction expenditure estimates made by Canadian businesses [32]. Agliardi and Sereno (2012), Hoffmann et al. (2012), $\mathrm{Hu}$ et al. (2014), Winchester et al. (2015), and Galinato and Galinato (2016) also found that government's public expenditure has a negative effect on carbon emissions [33-37].

Foreign scholars have made many meaningful explorations about the effect of governance on regional emissions reduction. Nevertheless, these studies were mostly targeted at developed countries in Europe and North America. Although a few scholars have analyzed the situation of developing countries in Latin America, their systematic analysis in China has not been reported. What is more, the existing research when considering the relationship between the two have not fully investigated the regional space spillover problem of regional emissions, but this phenomenon is ubiquitous.

Therefore, this paper aims to disclose the effect of governance on regional emissions reduction in China. The main contribution of this research has 3 aspects:

1) By using the spatial data exploration method, this paper analyzes the spatial correlation and spatial spillover characteristics of regional $\mathrm{CO}_{2}$ emissions.

2) This paper systematically examines the relationship between good governance and $\mathrm{CO}_{2}$ emissions from 3 aspects such as the level of regional legal regulation, the level of public expenditure, and the level of corruption. 
3) Based on empirical analysis, this paper provides beneficial policy recommendations to reduce carbon emissions.

\section{Material and Methods}

\section{Research Methods}

The term spatial autocorrelation refers to analyzing the correlation of the same variable in different spatial locations. The analysis method includes global spatial autocorrelation and local spatial autocorrelation. There are 3 possible results: positive spatial autocorrelation, negative spatial autocorrelation, and no spatial autocorrelation [38].

\section{The Theory and Method of Global Spatial Autocorrelation}

Global spatial autocorrelation detects the spatial pattern of the whole research area and uses a single value to reflect the autocorrelation of the entire region. In this paper, the global spatial autocorrelation index is adopted to test the global spatial autocorrelation [39]. The global spatial autocorrelation index is denoted as Global Moran's I. The calculation process is given in formula (1):

$$
\begin{aligned}
& I=\frac{n \sum_{i=1}^{n} \sum_{j=1}^{n} w_{i j}\left(x_{i}-\bar{x}\right)\left(x_{j}-\bar{x}\right)}{\sum_{i=1}^{n} \sum_{j=1}^{n} w_{i j} \sum_{i=1}^{n}\left(x_{i}-\bar{x}\right)}= \\
& =\frac{n \sum_{i=1}^{n} \sum_{j=1}^{n} w_{i j}\left(x_{i}-\bar{x}\right)\left(x_{j}-\bar{x}\right)}{S^{2} \sum_{i=1}^{n} \sum_{j=1}^{n} w_{i j}} \\
& s^{2}=\frac{1}{n} \sum_{i=1}^{n}\left(x_{i}-\bar{x}\right)^{2}, \bar{x}=\frac{1}{n} \sum_{i=1}^{n} x_{i}
\end{aligned}
$$

...where $I$ is the global spatial autocorrelation index; $n$ is the number of spatial unit data; $x_{i}$ and $x_{j}$ are the attribute values of the spatial units $i$ and $j$, respectively; and $w_{i j}$ is the spatial weight coefficient matrix to describe the adjacency relation of each spatial unit.

\section{The Theory and Method of Local Spatial Autocorrelation}

Local spatial autocorrelation detects the association between each spatial unit and its neighbors on a certain attribute. It can be expressed by local indicators of spatial association (LISA). According to the properties of spatial autocorrelation, this paper calculates the autocorrelation of a local region by local autocorrelation index, which is denoted as Local Moran's I. The calculation process is given in Formula (2).

$$
I_{i}=\frac{\left(x_{i}-\bar{x}\right) \sum_{j=1}^{n} w_{i j}\left(x_{j}-\bar{x}\right)}{S^{2}}
$$

...where $I_{i}$ is the local spatial autocorrelation index; $n$ is the number of spatial unit data; $x_{\mathrm{i}}$ and $x_{\mathrm{j}}$ are the attribute values of the spatial units $i$ and $j$, respectively; and $w_{\mathrm{ij}}$ is the spatial weight coefficient matrix to describe the adjacency relationship of each spatial unit.

\section{Establishing the Spatial Weight Matrix}

The spatial weight matrix expresses the spatial arrangement of the observable variables between different regions [40]. The adjacent relationships between several regions are often illustrated by a binary symmetric spatial weight matrix $(W)$. The matrix is expressed as below:

$$
w=\left[\begin{array}{cccc}
w_{11} w_{12} & \ldots & w_{1 n} \\
w_{21} & w_{22} & \ldots & w_{2 n} \\
\vdots & \vdots & \vdots & \vdots \\
w_{n 1} & w_{n 2} & \ldots & w_{n n}
\end{array}\right]
$$

... where $n$ is the total number of regions and $W_{i j}$ is the adjacency relationship between regions $i$ and $j$. In this research, the weight matrix is constructed based on the spatial adjacency relationship. In other words, if region $i$ and region $j$ share a common vertex or common boundary, $W_{i j}$ is 1 ; otherwise, $W_{i j}$ is 0 .

\section{Model Building}

The spatial econometric model for the effect of governance on regional emission reduction is constructed based on the EKC research results obtained by Grossman and Krueger (1994), Seldon and Song (1994), and the model used by Gani (2012) [10, 41-42]. According to Anselin (1995), classical spatial econometric models include spatial lag model (SLM) and spatial error model (SEM) [43]. As it is impossible to determine which of the 2 models is superior during the modeling phase, 2 types of model are designed to thoroughly reveal the effect of governance on regional emission reduction [39]. The SLM model is expressed by Formula (4) and the SEM model by Formula (5):

$$
\begin{aligned}
\ln C O_{2 i t} & =\rho W \ln C O_{2 i t}+\alpha_{0}+\alpha_{1} \ln p c g d p_{i t}+\alpha_{2} \ln ^{2} p c g d p_{i t}+\alpha_{3} \ln r o l_{i t} \\
& +\alpha_{4} \ln g m e_{i t}+\alpha_{5} \ln r c_{i t}+\alpha_{6} X_{i t}+\varepsilon_{i t}, \varepsilon_{i t} \sim N\left(0, \sigma_{i t}^{2}\right)
\end{aligned}
$$

$\ln C O_{2 i t}=\beta_{0}+\beta_{1} \ln p c g d p_{i t}+\beta_{2} \ln ^{2} p c g d p_{i t}+\beta_{3} \ln r o l_{i t}+\beta_{4} \ln g m e_{i t}+$ $\beta_{5} \ln r c_{i t}+\beta_{6} X_{i t}+\varepsilon_{i t}, \varepsilon_{i t}=\lambda W \varepsilon+\mu_{i t}, \varepsilon_{i t} \sim N\left(0, \sigma_{i t}^{2}\right)$ 
...where subscripts $i$ and $t$ represent region and year, $\operatorname{lnCO} O_{2 i t}$ denotes $\mathrm{CO}_{2}$ emissions, $\ln p c g d p_{i t}$ is the per capita GDP, $\ln r o l_{i t}$ represents the level of legal regulation, $\operatorname{lngme}_{i t}$ is the level of government public expenditure, $\ln r c_{i t}$ is the level of corruption, and $X_{i t}$ is other control variables affecting regional $\mathrm{CO}_{2}$ emissions. In Formula (4), $W \ln C O_{2 i t}$ is the spatial lag variable, $\rho$ is the spatial spillover effect of the $\mathrm{CO}_{2}$ emissions, and its values fall between -1 and 1 , and $\varepsilon$ is the independent random error vector. In Formula (5), $\lambda$ is the spatial error autocorrelation coefficient and its values fall between -1 and 1 , and $\mu_{i t}$ is the random distribution vector of normal distribution.

\section{Data Source and Index Selection}

The carbon emission targets are mainly calculated according to the method of the Intergovernmental Panel on Climate Change (IPCC). Since fossil energy consumption is the main source of carbon emissions, this paper computes $\mathrm{CO}_{2}$ emissions in light of the energy consumption data of the provinces over the years. According to the China Energy Statistical Yearbook, there are ultimately 9 major categories of energy consumption: coal, coke, crude oil, gasoline, kerosene, diesel oil, fuel oil, natural gas, and electricity. Considering that electricity is produced through the consumption of other types of energy, it is not taken into account to avoid duplication. In order to calculate the $\mathrm{CO}_{2}$ emissions of each province, the total energy consumption of the first 8 types of energy is multiplied by the respective carbon emissions coefficient. The formula is as follows:

$$
C_{i t}=\sum\left(E_{i j t} \bullet \eta_{j}\right)
$$

$\ldots$ where $C_{i t}$ is the total $\mathrm{CO}_{2}$ emissions of province $i$ in year $t ; E_{i j t}$ is the consumption of the $j$-th type of energy of province $i$ in year $\mathrm{t}$; and $\eta_{j}$ is the carbon emission coefficient of the $j$-th type of energy.

In the original statistics, the consumptions of various types of energy are physical statistics that must be converted to standard statistics for measuring carbon emissions. The conversion method is provided in the China Energy Statistical Yearbook (2008): coal equals $0.7143 \mathrm{~kg}$ standard coal $/ \mathrm{kg}$, coke equals $0.9714 \mathrm{~kg}$ standard coal $/ \mathrm{kg}$, crude oil and fuel oil equal $1.4286 \mathrm{~kg}$ standard coal $/ \mathrm{kg}$, gasoline and kerosene equal $1.4714 \mathrm{~kg}$ standard coal $/ \mathrm{kg}$, diesel oil equals $1.4571 \mathrm{~kg}$ standard coal $\mathrm{kg}$, natural gas equals $13.300 \mathrm{t}$ standard coal $/ 104 \mathrm{~m}^{3}$, and electricity equals $1.229 \mathrm{t}$ standard coal/104 $\mathrm{kWh}$. This paper also put the carbon emission coefficients of various types of energy as: coal equals $0.7476 \mathrm{t}$ carbon/t standard coal, gasoline equals $0.5532 \mathrm{t}$ carbon/t standard coal, diesel oil equals $0.5913 \mathrm{t}$ carbon/t standard coal, natural gas equals $0.4479 \mathrm{t}$ carbon/t standard coal, kerosene equals $0.3416 \mathrm{t}$ carbon/t standard coal, fuel oil equals $0.6176 \mathrm{t}$ carbon/t standard coal, crude oil equals $0.5854 \mathrm{t}$ carbon/t standard coal, and coke equals $0.1128 \mathrm{t}$ carbon/t standard coal [44].

In this paper, the level of governance is measured from 3 aspects. With regard to the level of legal regulation of a region, Han and Li (2005), Hu et al. (2012), Li et al. (2014), Ang et al. (2014), and Li and Wang (2015) believe that the degree of intellectual property protection in a region can reflect the level of legal regulation, and the higher degree of intellectual property protection in a region, the higher level of legal regulation [45-49]. Although the World Bank (WB) and World Economic Forum (WEF) have developed the measure of property rights such as property rights and property right and rule-based government ratings for a country, there are no indicators based on the provincial level. Therefore, drawing lessons from $\mathrm{Han}$ and $\mathrm{Li}$ (2005), Hu et al. (2012), and Li and Wang(2015), the level of legal regulation of a region is described by the size of regional technology transfer market in each province. The level of a government's public expenditure is depicted by the ratio of budgetary income to GDP in reference to the findings of $\mathrm{Li}$ and Feng (2011), Hu et al. (2014), and $\mathrm{Li}$ and Wang (2015) [37, 49-50]. According to the strategy adopted by scholars like Wan and Wu (2012), Li and Liu (2013), and Liao and Xia (2015), the level of corruption is characterized by the number of corruption cases reported by the procuratorial organ in each province [40, 51-52].

This paper considers the impact of trade openness (trd) and industrial structure (ic) on regional $\mathrm{CO}_{2}$ emissions. Trade openness is put into consideration

Table 1. Definition of variables and descriptive statistical results.

\begin{tabular}{|c|c|c|c|c|c|}
\hline variables & Unit & Minimum & Maximum & Mean & Std. Deviation \\
\hline $\mathrm{LnCO}_{2}$ & $10^{4}$ tons & 6 & 10 & 8.6806 & 0.893 \\
\hline Lnpcgdp & yuan & 8 & 11 & 9.7194 & 0.6975 \\
\hline $\operatorname{Ln}^{2} p c g d p$ & yuan & 65 & 126 & 94.525 & 12.4964 \\
\hline Lnrol & $10^{4}$ yuan & 8 & 17 & 12.4528 & 1.68 \\
\hline Lngme & $\%$ & 1 & 3 & 2.0222 & 0.3413 \\
\hline Lnrc & case & 5 & 8 & 6.7861 & 0.7873 \\
\hline Lntrd & $\%$ & 1 & 5 & 2.9472 & 1.0739 \\
\hline Lnic & $\%$ & 3 & 4 & 3.8278 & 0.3781 \\
\hline
\end{tabular}




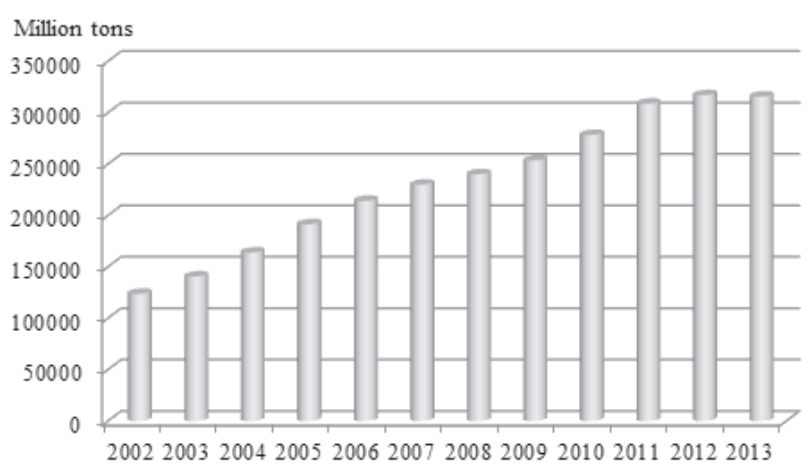

Fig. 1. Chinese $\mathrm{CO}_{2}$ emissions statistics, 2002-2013.

because many developed countries have tried to reduce emissions by shifting heavily polluting industries to developing countries with relatively low GHG emissions [53]. According to Gani (2012) and Hassaballa (2015), trade openness is measured by the percentage of trade share in gross domestic product $[10,21]$. The industrial structure is examined in view of the significant difference in environmental pollution and $\mathrm{CO}_{2}$ emissions of different industries. When industry takes up a major portion in a country's industrial structure, the country is highly likely to face high pollution and high emissions [54]. Drawing lessons from Li and Wang (2015), industrial structure is measured by the proportion of the secondary industry in GDP [37].

Carbon dioxide data from the China Energy Statistics Yearbook and the number of corruption and malfeasance cases are extracted from the annual work reports by regional people's procuratorates in procuratorialyearbooks of China, other data are derived from the corresponding year's China Statistical Yearbook. Furthermore, all variables are subjected to logarithmic treatment in order to eliminate the possible heteroscedasticity between them. The variable definitions and descriptive statistical results are shown in Table 1.

\section{Results and Discussion}

\section{Current Status and Spatial Correlation Analysis of $\mathrm{CO}_{2}$ Emissions in China}

Fig. 1 describes the trend of China's carbon emissions from 2002 to 2013. In the research period, the nationwide $\mathrm{CO}_{2}$ emissions increased continuously from 1.237 billion tons in 2002 to 3.16 billion tons in 2012. Starting from 2011, however, the growth of $\mathrm{CO}_{2}$ emissions significantly slowed and turned negative for the first time in 2013, when carbon emissions stood at 3.15 billion tons - lower than in 2012. The turn of the tide is attributable to the fact that the Chinese government began to implement $\mathrm{CO}_{2}$ emission reduction policies and adhere to the national strategy of low carbon development that began in 2009.

In terms of spatial distribution, there are obvious differences in $\mathrm{CO}_{2}$ emissions among the provinces. Fig. 2 shows the total and average $\mathrm{CO}_{2}$ emissions of Chinese provinces from 2002 to 2013. Overall, Shandong ranks first in total carbon emissions (2.65 billion tons) during these years, followed by Shanxi, Hebei, Jiangsu, and Liaoning. These provinces boast high carbon emissions due to the concentration of heavy and/or coal industries. Qinghai and Hainan rank the lowest and second lowest in total carbon emissions. From 2002 to 2013, the total carbon emissions of Shandong were about 30 times that of Qinghai and 25 times that of Hainan.

$$
\begin{gathered}
\text { Spatial Correlation of } \mathrm{CO}_{2} \text { Emissions } \\
\text { in China }
\end{gathered}
$$

During the exploration into the spatial correlation of $\mathrm{CO}_{2}$ emissions in China, this paper first calculated the global Moran I values by exploratory spatial data analysis to test the spatial correlation of $\mathrm{CO}_{2}$ emissions in China, and then verified the spatial distribution pattern by Moran scatter plot and LISA aggregation map.

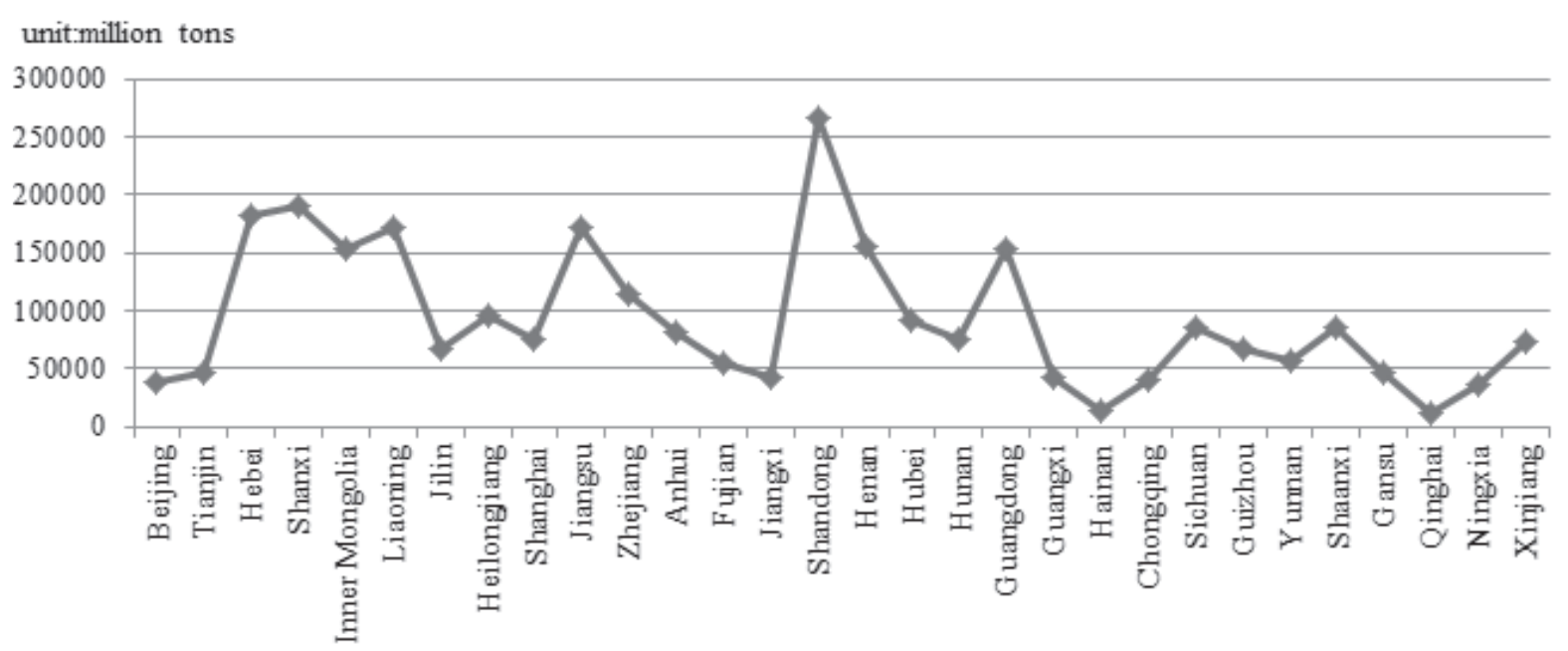

Fig. 2. Total $\mathrm{CO}_{2}$ emissions of each province in China, 2002-2013. 
Table 2. Global Moran I values of $\mathrm{CO}_{2}$ emissions in China, 2002-2013.

\begin{tabular}{|c|c|c|}
\hline Years & Moran I & p-value \\
\hline 2002 & 0.2507 & 0.02 \\
\hline 2003 & 0.2241 & 0.022 \\
\hline 2004 & 0.2586 & 0.013 \\
\hline 2005 & 0.2852 & 0.009 \\
\hline 2006 & 0.2741 & 0.008 \\
\hline 2007 & 0.2747 & 0.008 \\
\hline 2008 & 0.2835 & 0.014 \\
\hline 2009 & 0.2618 & 0.01 \\
\hline 2010 & 0.2602 & 0.014 \\
\hline 2011 & 0.2652 & 0.009 \\
\hline 2012 & 0.2475 & 0.015 \\
\hline 2013 & 0.2515 & 0.011 \\
\hline & & \\
\hline
\end{tabular}

\section{Global Spatial Autocorrelation Analysis}

This paper calculates global Moran I values of $\mathrm{CO}_{2}$ emissions of 30 Chinese provinces in 2002-2013 by OpenGeoDa1.2, tests the significance of the indices, and examines the overall correlation of $\mathrm{CO}_{2}$ emissions in China. The results are shown in Table 2.

The spatial positive autocorrelation of carbon emissions is relatively stable between Chinese provinces. As shown in Table 2, all the global Moran I values of $\mathrm{CO}_{2}$ emissions in 30 Chinese provinces exceed 0.2 from 2002 to 2013, and surpass the significance level of 5\%, revealing significant spatial positive correlation of $\mathrm{CO}_{2}$ emissions in China. Meanwhile, the global Moran's I values from 2002 to 2013 fall between 0.2 and 0.3 , showing a trend of volatility. However, the fluctuation is insignificant and the overall trend is rather stable. Whereas the values are greater than $0, \mathrm{CO}_{2}$ emissions in China are not randomly distributed. Instead, the distribution bears some features of spatial clustering: high-carbon emission areas are adjacent to high-carbon emission areas, and low-carbon emission areas are adjacent to low-carbon emission areas.

\section{Local Spatial Autocorrelation Analysis}

OpenGeoDa1.2 is used to calculate the local Moran's values of $\mathrm{CO}_{2}$ emissions to obtain the Moran scatter plots in 30 Chinese provinces from 2002 to 2013. Due to space limitations, 2002, 2007, and 2013 are selected as typical years for analysis. The results are shown in Fig. 3.

As can be seen from Fig. 3, most Chinese provinces are distributed in the first and third quadrants of Moran scatter plots. 18 provinces fall into these quadrants in any of the 3 typical years $(8$ in the first quadrant, 10 in the third quadrant). Overall, $60 \%$ of the provinces are located in the first and third quadrants of Moran scatter plots in the 3 years, respectively. The distribution further testifies that $\mathrm{CO}_{2}$ emissions in China exhibit significant spatial autocorrelation.

For further identification, the local spatial correlation mode of $\mathrm{CO}_{2}$ emissions in China and LISA cluster maps are used to test the spatial correlation degree of local areas. The results are shown in Fig. 4.

As can be seen from Fig. 4, the Chinese provinces form different cluster regions in the local spatial distribution of regional $\mathrm{CO}_{2}$ emissions. The high-emission high-high cluster region concentrated in Shandong, Hebei, and Henan in 2002; Shandong, Hebei, Henan, Inner Mongolia, and Helongjiang in 2007; and Shandong, Hebei, Henan, and Inner Mongolia in 2013. The high carbon emission cluster region centers on Shandong, Hebei, and Henan; the region expands from 2002 to 2007 but shrinks from 2007 to 2013. In the end, the size of the high-high cluster region is larger in 2013 than 2002. The low-emission low-low cluster region is concentrated in Qinghai and Sichuan in 2002, and Sichuan and Guangxi in 2013. The low-low agglomeration region is shifting to the eastern part of China. The high-low cluster region, however, always was in Guangdong in 2002, 2007, and 2013. This shows that Guangdong, as a high-carbon emissions area, is perennially surrounded by low-carbon emission areas, and the spatial pattern is relatively stable. The provinces belonging to the low-high agglomeration region in 2002 gradually became part of the high-high cluster region.
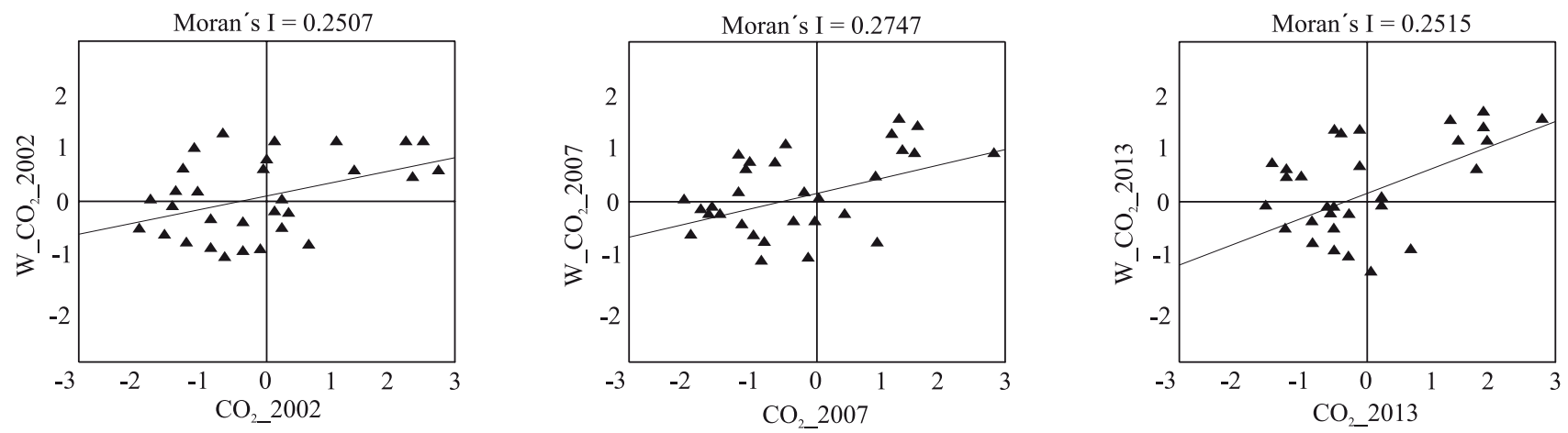

Fig. 3. Moran scatter plots of provincial $\mathrm{CO}_{2}$ emissions in 2002, 2007, 2013. 

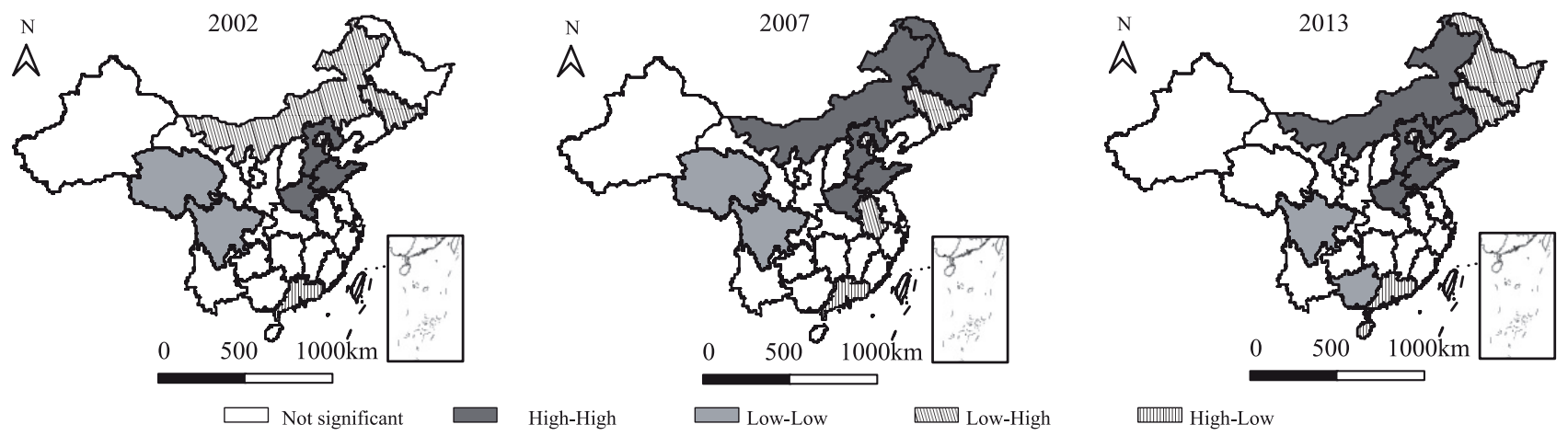

Fig. 4. LISA cluster maps of $\mathrm{CO}_{2}$ emissions in China 2002, 2007, 2013.

According to the analysis of LISA cluster maps of $\mathrm{CO}_{2}$ emissions in China in 2002, 2007, and 2013, the high-carbon emissions high-high cluster region has expanded from 2002 to 2013. Part of the low-carbon emissions low-high cluster region has gradually evolved into high-carbon emissions high-high cluster region, lowcarbon emissions low-low cluster region is shifting to the eastern part of China, and the high-low cluster region remains relatively stable.

\section{Spatial Econometric Test of the Effect of Government Governance on $\mathrm{CO}_{2}$ Emissions}

\section{Spatial Correlation Test and Model Selection}

Before analyzing the spatial relationship between government governance and regional carbon dioxide emissions, SLM and SEM need to be selected. In this paper, the model is tested by spatial autocorrelation. The results are shown in Table 3. From the results in Table 3, the LM test of no spatial lag value is 19.6866 , and through the $1 \%$ significance level test, LM test of no spatial error test value is 17.3192 , but does not pass the significance test, indicating that the SLM model is better than the SEM model. Therefore, the SLM model is used to start empirical analysis in the following.

Table 3. Spatial correlation test of regional $\mathrm{CO}_{2}$ emissions in China.

\begin{tabular}{|c|c|c|}
\hline Testing method & Teststatistics & P-value \\
\hline $\begin{array}{c}\text { LM test no spatial lag, } \\
\text { probability }\end{array}$ & 19.6866 & 0.0000 \\
\hline $\begin{array}{c}\text { robust LM test no spatial lag, } \\
\text { probability }\end{array}$ & 3.4884 & 0.0620 \\
\hline $\begin{array}{c}\text { LM test no spatial error, } \\
\text { probability }\end{array}$ & 17.3192 & 0.0000 \\
\hline $\begin{array}{c}\text { robust LM test no spatial } \\
\text { error, probability }\end{array}$ & 1.1210 & 0.2900 \\
\hline
\end{tabular}

\section{Estimated Results of Spatial Econometric Model}

Matlab 2016a is used for empirical analysis on the SLM model, aimed at disclosing the effect of governance on regional $\mathrm{CO}_{2}$ emissions from 4 aspects: non-fixed effect (NFE), spatial-fixed effect (SFE), time periodfixed effect (TFE), and space and time period-fixed effect (STFE). The empirical results are shown in Table 4.

Geographic proximity has a significant positive impact on China's regional $\mathrm{CO}_{2}$ emissions. According to the results of NFE, SFE, TFE, and STFE of SLM, the spatial lag coefficients $\rho$ of the four models are 0.0700 , $0.2340,0.0280$, and -0.0560 , respectively. The spatialfixed effect model is the only one with a significant spatial lag coefficient $\rho$ at the $1 \%$ level - evidence for the spatial autocorrelation of regional $\mathrm{CO}_{2}$ emissions in China. If the adjacent areas have high $\mathrm{CO}_{2}$ emissions, the local region tends to have large $\mathrm{CO}_{2}$ emissions. The spatial lag coefficient $\rho$ stands at 0.2340 , indicating that the $\mathrm{CO}_{2}$ emissions in the region increase by $0.234 \%$ for each additional $1 \%$ of $\mathrm{CO}_{2}$ emissions in the adjacent areas. Thus, the $\mathrm{CO}_{2}$ emissions reflect the spatial clustering phenomenon.

Secondly, governance has a significant impact on regional emissions reduction. From the empirical results of the SFE model, it can be seen that the level of legal regulation is negatively correlated with the regional $\mathrm{CO}_{2}$ emissions at the significance level of $1 \%$. This means that the stricter the level of legal regulation, the lower the level of regional carbon emissions, indicating that the implementation of emission reduction policies and regulations help to decrease $\mathrm{CO}_{2}$ emissions. Thus, good legal regulation is beneficial to the realization of emission reduction targets. The level of government public expenditure is also positively correlated with $\mathrm{CO}_{2}$ emissions at the significance level of $1 \%$, indicating that the government emission reduction expenditure provides financial support to enterprises, promotes the enterprises' emission reduction practice, and leads to the decline of $\mathrm{CO}_{2}$ emissions. The regional corruption is negatively correlated with regional $\mathrm{CO}_{2}$ emissions at the significance level of $10 \%$, signifying that the higher the degree of corruption, the lower the level of regional carbon emissions. Thus, the immense impediment of 
Table 4. Spatial econometric test results.

\begin{tabular}{|c|c|c|c|c|}
\hline \multirow{2}{*}{ Variables } & NFE & SFE & TFE & STFE \\
\hline & Coefficient & Coefficient & Coefficient & Coefficient \\
\hline intercept & $\begin{array}{c}-12.8229 * * * \\
(-2.9081)\end{array}$ & & & \\
\hline Lnpcgdp & $\begin{array}{c}2.2192 * * \\
(2.4456)\end{array}$ & $\begin{array}{c}1.3468^{* * * *} \\
(4.1100)\end{array}$ & $\begin{array}{c}1.1288 \\
(1.1903)\end{array}$ & $\begin{array}{c}1.6458 * * * \\
(5.1959)\end{array}$ \\
\hline $\operatorname{Ln}^{2} p c g d p$ & $\begin{array}{l}-0.0830^{*} \\
(-1.7605)\end{array}$ & $\begin{array}{c}-0.0394 * * \\
(-2.4027)\end{array}$ & $\begin{array}{c}-0.0281 \\
(-0.5795)\end{array}$ & $\begin{array}{c}-0.0578 * * * \\
(-3.4837)\end{array}$ \\
\hline Lnrol & $\begin{array}{c}-0.0197 \\
(-0.9360)\end{array}$ & $\begin{array}{c}-0.0580 * * * \\
(-4.9965)\end{array}$ & $\begin{array}{c}-0.0175 \\
(-0.8119)\end{array}$ & $\begin{array}{c}-0.0585^{* * *} \\
(-5.0478)\end{array}$ \\
\hline Lngme & $\begin{array}{c}0.4712 * * * \\
(4.6300)\end{array}$ & $\begin{array}{c}0.2554 * * * \\
(5.1693)\end{array}$ & $\begin{array}{c}0.4497 * * * \\
(3.9054)\end{array}$ & $\begin{array}{c}0.3428 * * * \\
(5.0442)\end{array}$ \\
\hline Lnrc & $\begin{array}{c}0.7771 * * * \\
(18.3499)\end{array}$ & $\begin{array}{l}-0.0550^{*} \\
(-1.6881)\end{array}$ & $\begin{array}{c}0.7998 * * * \\
(17.9184)\end{array}$ & $\begin{array}{c}0.0044 \\
(0.1314)\end{array}$ \\
\hline Lntrd & $\begin{array}{c}-0.1791 * * * \\
(-5.6175)\end{array}$ & $\begin{array}{c}-0.1161 * * * \\
(-4.4642)\end{array}$ & $\begin{array}{c}-0.1770 * * * \\
(-3.7581)\end{array}$ & $\begin{array}{c}-0.1647 * * * \\
(-5.9520)\end{array}$ \\
\hline Lnic & $\begin{array}{c}0.4715^{* * *} \\
(5.0527)\end{array}$ & $\begin{array}{c}0.2774 * * * \\
(4.3907)\end{array}$ & $\begin{array}{c}0.4381 * * * \\
(4.4006)\end{array}$ & $\begin{array}{c}0.1952 * * * \\
(2.9525)\end{array}$ \\
\hline$\rho / \lambda$ & $\begin{array}{c}0.0700 \\
(1.5045)\end{array}$ & $\begin{array}{c}0.2340 * * * \\
(4.2959)\end{array}$ & $\begin{array}{c}0.0280 \\
(0.6109)\end{array}$ & $\begin{array}{c}-0.0560 \\
(-0.8247)\end{array}$ \\
\hline $\mathrm{R} 2$ & 0.7576 & 0.9003 & 0.7370 & 0.9857 \\
\hline Log likelihood & -173.2517 & 308.6489 & -161.9043 & 331.8725 \\
\hline
\end{tabular}

Note: Figures in parentheses are t-statistics, $* * *, * *$ and $*$ indicate the significance at $1 \%, 5 \%$, and $10 \%$ level, respectively.

regional corruption to regional emission reduction is not supported. A possible reason is that corruption breeds rent-seeking behavior, which hinders economic growth and reduces regional carbon dioxide emissions.

Then, there is an inverted "U"-shaped relationship between per capita GDP and $\mathrm{CO}_{2}$ emissions. According to Table 4, the first and second terms of per capita GDP have a significant effect on the growth of $\mathrm{CO}_{2}$ emissions. The corresponding $\mathrm{T}$ statistics are 4.1100 and -2.4027 , respectively. The first term is significantly positively correlated with $\mathrm{CO}_{2}$ emissions at the $1 \%$ level, and the second term is significantly negatively correlated with $\mathrm{CO}_{2}$ emissions at the $5 \%$ level. The results demonstrate the inverted "U"-shaped relationship between economic income and $\mathrm{CO}_{2}$ emissions, and confirm that at the beginning of economic development, the overall $\mathrm{CO}_{2}$ emissions of the country with the increase of economic income; when the level of economic development reaches a certain height, the $\mathrm{CO}_{2}$ emissions will slow despite further increases in national economic income. In other words, there is an inverted "U"-shaped relationship between the level of economic development and $\mathrm{CO}_{2}$ emissions.

In addition, economic openness and industrial structure are 2 major influencing factors of regional $\mathrm{CO}_{2}$ emissions. The empirical results of spatial-fixed effect show that economic openness is negatively correlated with regional $\mathrm{CO}_{2}$ emissions: the higher the degree of regional economic openness, the freer the trade and the lower the $\mathrm{CO}_{2}$ emissions in the region. The significant positive correlation between industrial structure and regional $\mathrm{CO}_{2}$ emissions demonstrates that regional $\mathrm{CO}_{2}$ emissions grow with the proportion of industry in the regional economy.

\section{Conclusions}

In this paper, the exploratory spatial data analysis is adopted to analyze the spatial correlation of regional $\mathrm{CO}_{2}$ emissions, and the spatial econometric model is used to test its effect on $\mathrm{CO}_{2}$ emissions. The main conclusions and policy implications are as follows.

First, the spatial positive autocorrelation of carbon emissions is relatively stable between Chinese provinces. The overall global Moran's I values from 2002 to 2013 fall between 0.2 and 0.3 , showing a trend of volatility. However, the fluctuation is insignificant and the overall trend is rather stable. As for the spatial distribution of $\mathrm{CO}_{2}$ emissions in Chinese provinces, the distribution bears some features of spatial clustering, and highcarbon emission areas are adjacent to high-carbon emission areas, and low-carbon emission areas are adjacent to low-carbon emission areas. Part of the lowcarbon emission low-high cluster region has gradually evolved into high-carbon emission high-high cluster region; the low-carbon emission low-low cluster region is shifting to the eastern part of China; and the high-low cluster region remains relatively stable. Second, governance has a significant impact on regional 
emissions reduction. From the empirical results it can be seen that the level of legal regulation and regional corruption are significantly negatively correlated with regional $\mathrm{CO}_{2}$ emissions, indicating that stricter law enforcement by the government can reduce regional $\mathrm{CO}_{2}$ emissions, and high levels of government corruption is conducive to reducing regional $\mathrm{CO}_{2}$ emissions. Meanwhile, the level of public expenditure is significantly positively correlated with regional $\mathrm{CO}_{2}$ emissions. Thus, more governmental financial support lowers $\mathrm{CO}_{2}$ emissions. Furthermore, the relationship between $\mathrm{CO}_{2}$ emissions and per capita GDP reveals the inverted "U"shape, which means that carbon emissions will increase with the increase of economic income in the beginning, when the economic income reaches a certain level, carbon emissions will decline.

Based on the above conclusions, the author comes up with the following suggestions:

1) In view of the spatial clustering features of regional $\mathrm{CO}_{2}$ emissions, the government should formulate governance policies targeted at specific agglomeration regions. For example, the high-carbon emission highhigh cluster region, as the key governance area, must be the focal point of attention and governance.

2) The government should further improve environmental laws and regulations, roll out detailed emission reduction policies, strengthen law enforcement and supervision, and promote the realization of emission reduction targets.

3) Since the government's public expenditure provides strong support to an enterprises' low-carbon emission reduction activities, the government must step up capital investment, create a special fund for corporate emissions reduction, and actively support enterprises to carry out emission reduction practices. Besides, the government should pay more attention to the management of corruption, in the empirical study, although corruption is conducive to reducing regional carbon emissions, whether is because corruption curbs economic growth and causes this phenomenon? Further study of the problem is required.

\section{Acknowledgements}

This study was supported by Guangdong Soft Science Item (No. 2016A070706008) and Foshan City Philosophy and Social Science Fund (No. 2017-GJ36).

\section{References}

1. JIANG FUXIN, WANG ZHUJUN, BAI JUNHONG. The dual effect of environmental regulation on technological innovation: an empirical study based on dynamic panel data of Jiangsu manufacturing industry. China Industrial Economy. (07), 44, 2013.

2. ZHANG HUA. Advances in environmental regulation competition. Environmental Economics Research. 4 (01), 99, 2017.
3. ZHANG HUA. A study on the strategic interaction of regional environmental Regulation-An explanation of the incomplete execution of environmental regulation. China Industrial Economy. 4 (07), 74, 2016.

4. ZHOU CHANGFU, DU YUWEI, PENG ANPING. Does environmental regulation affect the location choice of FDI in China?-empirical study based on cost perspective. World Economic Studies. 1 (01), 110, 2016.

5. GAO ZHENGPING, ZHANG XINGWEI. Social capital, government governance and regional enterprises' in vitro capacity: an empirical study based on provincial data in china. Financial and Economic. (9), 121, 2013.

6. ACEMOGLU DARON, JOHNSON SIMON, ROBINSON JAMES A. Institutions as a fundamental cause of long-run growth. Handbook of economic growth. 1, 385, 2005.

7. HUANG RONGBING. Environmental auditing: an informationized regulatory tool of carbon emission reduction. Energy Procedia. 5, 6, 2011.

8. FANG YUAN. Research on evolutionary game of off shore environmental regulation under emission-reduction constraint in China. Ecological Economy. 58 (22), 315, 2013.

9. DU XIAOWEI. Policy constructing of energy-saving and emission-reduction: based on the perspective of environmental regulation. Ecological Economy. 3 (2), 67, 2013.

10. GANI AZMAT. The relationship between good governance and carbon dioxide emissions: Evidence from developing economies. Journal of Economic Development. 37 (1), 77, 2012.

11. ZHANG HUA, WEI XIAOPING. Green Paradox or forced emission-reduction: dual effect of environmental regulation on carbon emissions. China Population Resources \& Environment. 24 (9), 21, 2014.

12. HUANG RONGBING, LI YUHUI, CHEN GENG. Environmental audit-based model on the regulation of the energy saving and emission reduction. Operations Research \& Management Science. 23 (01), 23, 2014.

13. XIU JING, LIU HAIYING. Energy conservation and emission reduction environmental regulations and Chinese industrial TFP. Nanjing Journal of Social Sciences. 1 (5), 27, 2014.

14. HAMPF BENJAMIN, RØDSETH KENNETH LØVOLD. Optimal profits under environmental regulation: the benefits from emission intensity averaging. Annals of Operations Research., 1, 2014.

15. HUANG QINGHUANG, GAO MING. A research on the energy conservation and emission reduction effect of China's environmental regulation tools. Science Research Management. 1 (1), 30, 2016.

16. CHENG ZHONGHUA, LI LIANSHUI, LIU JUN. The emissions reduction effect and technical progress effect of environmental regulation policy tools. Journal of Cleaner Production. 149, 191, 2017.

17. BASSIOUNI M. CHERIF. Nexus between corruption and regional Environmental Kuznets Curve: the case of South Asian countries. Environment Development \& Sustainability. 14 (5), 827, 2012.

18. COLE MATTHEW A. Corruption, income and the environment: an empirical analysis. Ecological Economics. 62 (3), 637, 2007.

19. NASREEN SAMIA, RIAZ MUHAMMAD FARAZ. Relationship between corruption, income inequality and environmental degradation in pakistan: an econometric analysis. Bulletin of Energy Economics (BEE). 4 (1), 12, 2016. 
20. OZTURK ILHAN, AL-MULALI USAMA. Investigating the validity of the environmental Kuznets curve hypothesis in Cambodia. Ecological Indicators. 76, 123, 2015.

21. HASSABALLA HODA. The effect of corruption on carbon dioxide emissions in the MENA region. European Journal of Sustainable Development. 4 (2), 301, 2015.

22. JIN SHENGWU, WU JUAN. Corruption, economic growth and the Environmental Kuznets curve. Economic Theory and Business Management. 6, 4, 2014.

23. LEITÃO ALEXANDRA. Corruption and the environmental Kuznets Curve: empirical evidence for sulfur. Ecological Economics. 69 (11), 2191, 2011.

24. SHACKLETON C.M., GUTHRIE G., MAIN R. The effects of corruption control, political stability and economic growth on deforestation-induced carbon dioxide emissions. Environment \& Development Economics. 17 (1), 67, 2012.

25. KHAN ARIF A., RUCHI SRIVASTAVA, CHENTOUFI AZIZ A., ROGER GEERTSEMA, THAI NHI THI UYEN, GARGI DASGUPTA, NELSON OSORIO, MINA KALANTARI, NESBURN ANTHONY B., WECHSLER STEVEN L. China: information on local government corruption and persecution of citizens. Shiyou Xuebao. 30 (3), 568, 2014

26. SUNDSTRÖM AKSEL. Corruption in the commons: Why bribery hampers enforcement of environmental regulations in South African Fisheries. International Journal of the Commons. 7 (2), 454, 2013.

27. ZHANG YUEJUN, JIN YANLIN, CHEVALLIER JULIEN, SHEN BO. The effect of corruption on carbon dioxide emissions in APEC countries: a panel quantile regression analysis. Technological Forecasting \& Social Change. 112, 220, 2016.

28. SEKRAFI HBIB, SGHAIER ASMA. Examining the relationship between corruption, economic growth, environmental degradation, and energy consumption: a panel analysis in MENA region. Journal of the Knowledge Economy., 1, 2016.

29. ESTY DANIEL C., PORTER MICHAEL E. National environmental performance: an empirical analysis of policy results and determinants. Environment and development economics. 10(04), 391-434, 2005

30. GALINATO GREGMAR. The role of government spending on deforestation and carbon dioxide emissions from land use change. Working Papers. 81 (2), 85, 2013.

31. XIAO H., LIU H., LIU Y. The effect of local government expenditure on $\mathrm{CO}_{2}$ emissions: an empirical investigation in China. International Journal of Applied Environmental Sciences. 8 (3), 271, 2013.

32. FRITZSCHE, JEFF. Canadian industry's expenditures to reduce greenhouse gas emissions. Envirostats., 1, 2013.

33. AGLIARDI ELETTRA, SERENO LUIGI. Environmental policies, public abatement spending and the timing of emission reductions. Ifac Proceedings Volumes. 45 (25), 176, 2012.

34. HOFFMANN PETER N., EIDE MAGNUS S., ENDRESEN ØYVIND. Effect of proposed $\mathrm{CO}_{2}$ emission reduction scenarios on capital expenditure. Maritime Policy \& Management. 39 (4), 443, 2012.

35. WINCHESTER NIVEN, MALINA ROBERT, STAPLES MARK D., BARRETT STEVEN R. H. The impact of advanced biofuels on aviation emissions and operations in the U.S. Energy Economics. 49 (1), 482, 2015.

36. GALINATO GREGMAR I., GALINATO SUZETTE P. The effects of government spending on deforestation due to agricultural land expansion and $\mathrm{CO}_{2}$ related emissions. Ecological Economics. 122, 43, 2016.
37. HU ZONGYI, ZHU LI, TANG LIWEI. A study on the carbon emission reduction effect of public expenditure of Chinese government. Chinese Population, Resources and Environment. 24 (10), 32, 2014.

38. WU HONG. Carbon emission reduction in China: spatial and temporal pattern, evolution mechanism and policy suggestions-theory and method based on spatial econometrics. Management World. (11), 3, 2015.

39. LI LI, TANG DENGLI, KONG YING, LIU DONGJUN, YANG YUANHUA. A study on the impact of FDI on urban Haze pollution: a case study of the Pearl River. Management Comment. 28 (6), 11, 2016.

40. LIAO XIANCHUN, XIA ENLONG. Why China attracts FDI inflows? a perspective of environmental stringency and the degree of corruptibility. World Economy Study. 1 (01), 112,2015

41. GROSSMAN GENE M., KRUEGER ALAN B. Economic growth and the environment. Quarterly Journal of Economics. 110 (2), 353, 1994.

42. SELDEN THOMAS M., SONG DAQING. Environmental quality and development: is there a Kuznets curve for air pollution emissions? Journal of Environmental Economics and Management. 27 (2), 147, 1994.

43. ANSELIN LUC. Local indicators of spatialassociationLISA. Geographical Analysis. 27 (2), 93, 1995.

44. LI GUOZHI, LI ZONGZHI. Study on regional difference and influencing factors of carbon dioxide emission in China. Chinese Population Resources and Environment. 20 (05), 22, 2010.

45. YUXIONG HAN, HUAIZU LI. A quantitative analysis of the protection level of intellectual property rights in China. Studies in Science of Science. 23 (3), 377, 2005.

46. KAI HU, QING WU, YUMIN HU. Technological innovation effect of intellectual property protection. Financial Research. 1 (08), 15, 2012.

47. LI LI, YAN BIN, GU CHUANXIA. Intellectual property protection, information asymmetry and high-tech enterprise capital structure. Management World. (11), 1, 2014.

48. ANG JAMES S., CHENG YINGMEI, WU CHAOPENG. Does enforcement of intellectual property rights matter in china? Evidence from financing and investment choices in the High-Tech industry. Review of Economics and Statistics. 96 (2), 332, 2014.

49. LIGUOZHANG, WANG BIN. Research on the construction of global system quality measurement system. Journal of Northwest Normal University. 52 (4), 122, 2015.

50. LIU ZHENGYONG, FENG HAIBO. Corruption, public expenditure efficiency and long-term economic growth. Economic Research. (09), 17, 2011.

51. LI ZIHAO, LIU HUIHUANG. Foreign direct investment, regional corruption and environmental pollution: an empirical study based on threshold effect. International Trade Issues. 7 (07), 50, 2013.

52. WAN GUANGHUA, WU YIPING. Institutional construction and anti-corruption: a study based on the change of inter-level corruption. Management World. 4, 60, 2012.

53. FRAME DAVID J., HEPBURN CAMERON. An issue of trust: state corruption, responsibility and greenhouse gas emissions. Environmental Research Letters. 5 (1), 123, 2010.

54. WANG XIAONING, ZHOU XIAOWEI. Marketization process, environmental regulation and economic growth: an empirical study based on eastern, middle, and western regions of China. Scientific Decision Making. (03), 82, 2015. 